\title{
Study on the Key Technology of Coal Wall Stability Control for Mining All Height at One Time in Thick Seam
}

\author{
Shu-Jiang CUI ${ }^{1}$, Jian-Ming $\mathrm{ZHU}^{2, a,{ }^{*}}$ \\ ${ }^{1}$ School of Resources and Safety Engineering, China University of Mining \& Technology Beijing \\ 100083, China \\ ${ }^{2}$ School of Civil Engineering, North China University of Technology, Beijing 100144, China \\ ajmzhu@263.net \\ ${ }^{*}$ Corresponding author
}

Keywords: Mining All Height at One Time, Coal Wall Spalling Mechanism, Width of Plastic Zone, Influencing Factors of Coal Wall Spalling, Control Technology.

\begin{abstract}
Combined with Lade-Duncan strength criterion under plane strain condition, the coal wall spalling mechanism has been analyzed, the width of plastic zone and stress distribution has been studied, has identified the several important influencing factors, and using numerical simulation method for more intensive study, finally, the key technology of coal wall stability control is put forward which includes increasing the support strength, using side supporting design and taking coal wall grouting, through the field monitoring test, having achieved a good practical result, it provides a effective technical guarantee for thick coal seam in Wang Zhuang coal mine.
\end{abstract}

\section{Introduction}

The technology of mining all height at one time has become an effective means for thick coal seam mining in recent years, it indicates that the coal recovery rate has increased 10\% 15\% than the fully mechanized top coal caving mining [1]. But the increase of mining height leads to the increase of stope space, causing severe pressure behavior and the coal wall spalling phenomenon. The coal wall spalling will cause serious damage to the equipment and personnel casualties [2], seriously restricting the development of full-seam mining technology, so the study on the key technology of coal wall stability control for mining all height at one time in thick seam has extremely important significance.

This paper takes Lu An Group Wang Zhuang coal mine 7105 full-seam mining working face for the practical background, based on the analysis of the coal wall spalling mechanism, takes a intensive study on the the influence factors, the key technology of coal wall stability control has been put forward, it has solved the thick seam mining technology problem in Wang Zhuang coal mine.

\section{Analysis of Coal Wall Spalling Mechanism}

After the excavation of coal body, under the abutment pressure, coal wall collapse first, produce large large number of joints, rapidly expansion to coal body, different angle of fracture fit together, the coal wall forms a plastic zone [3]. The plastic zone is the direct cause of coal wall spalling, study on the coal wall plastic zone width and stress distribution is the priority task of coal wall stability control.The coal body stress state in front of the working face is as shown in Figure 1.

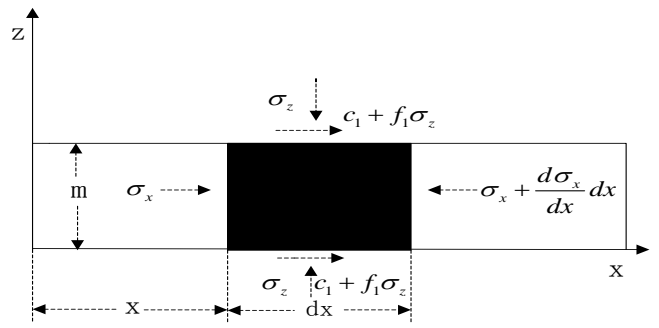

Fig. 1 The Limit Equilibrium State of Stress 
According to the equilibrium condition of unit body $\sum F_{x}=0$, equilibrium equation can be identified, $m \sigma_{x}+2\left(c_{1}+f_{1} \sigma_{z}\right) d x-m\left(\sigma_{x}+\frac{d \sigma_{x}}{d x} d x\right)=0$. Simplified as,

$$
2\left(c_{1}+f_{1} \sigma_{z}\right)-m \frac{d \sigma_{x}}{d x}=0 .
$$

Because one side of the coal wall horizontal direction is mined-out area, the horizontal stress is released, so $\sigma_{z}$ is larger than $\sigma_{x}$, and the angle between $\sigma_{z}$ and $\sigma_{1}$, between $\sigma_{x}$ and $\sigma_{3}$ is very small, it can be considered that $\sigma_{x}$ as the minor principal stress, $\sigma_{z}$ as the major principal stress [4]. When the coal yields, it meets the Lade-Duncan criterion of plane strain suitable for viscous materials which is derived in the paper [5]. Using it in the formula (1):

$$
\ln \left(c_{1}+f_{1} \sigma_{z}\right)=\frac{2 \eta f_{1} x}{m}+D
$$

In the formula, $\eta=\frac{1}{4}\left[\sqrt[3]{K}-1+\sqrt{(\sqrt[3]{K}-1)^{2}-4}\right]^{2}, \mathrm{D}$ is a constant.

By using the boundary condition to calculate $\mathrm{D}$, when $x=0, \sigma_{x}=p$, using the formula (2),

$$
D=\ln \left(c_{1}+f_{1} \eta p+f_{1} \eta \sigma_{0}-f_{1} \sigma_{0}\right) .
$$

Bring formula (3) into (2),

$$
\sigma_{z}=e^{\frac{2 \eta f_{1} x}{m}}\left(\frac{c_{1}}{f_{1}}+\eta \sigma_{0}+\eta p-\sigma_{0}\right)-\frac{c_{1}}{f_{1}} \text {. }
$$

In the formula, $p$ is the support resistance of side protecting plate to coal wall.

The maximum support pressure in the elastic-plastic boundary is as below:

$$
\sigma_{z}=k_{1} \gamma H \text {. }
$$

In the formula, $k_{1}$ is the stress concentration factor, normally 2 4. Bring formula (5) into formula (4), the plastic width of coal wall can be calculated,

$$
x=\frac{m}{2 \eta f_{1}} \ln \frac{c_{1}+f_{1} k_{1} \gamma H}{c_{1}+f_{1}\left(\eta \sigma_{0}+\eta p-\sigma_{0}\right)} .
$$

$$
\text { In the formula, } \left.\quad \eta=\frac{1}{4}\left[\sqrt[3]{K}-1+\sqrt{(\sqrt[3]{K}-1)^{2}-4}\right]^{2} \quad K=\frac{\left(3-\operatorname{sim}^{3}\right)}{(1+\operatorname{sim})\left(-1 \quad s \dot{\rho} n^{2}\right.}\right)
$$

Therefore, the formula (6) is the calculating formula of the coal wall plastic width based on the Lade-Duncan criterion under plane strain condition. The formula (6) shows that the strength of the support, side protecting plate resistance, strength of coal body, coal mining height and depth of coal seam are several important factors that affect the width of plastic zone, improving the supporting strength, increasing the side protecting plate support resistance, changing coal properties are the effective ways to reduce the coal wall plastic width and control the coal wall spalling.

\section{Effect of Hydraulic Support Strength on the Stability of the Coal Wall}

According to the specific conditions of 7105 working face in Wang Zhuang coal mine, use FLAC3D software to simulate the coal wall stability on full-seam mining working face. Figure 2 is the relationship diagram between support strength and roof subsidence displacement. Figure 3 is the maximum horizontal displacement of coal wall with different support strength. 


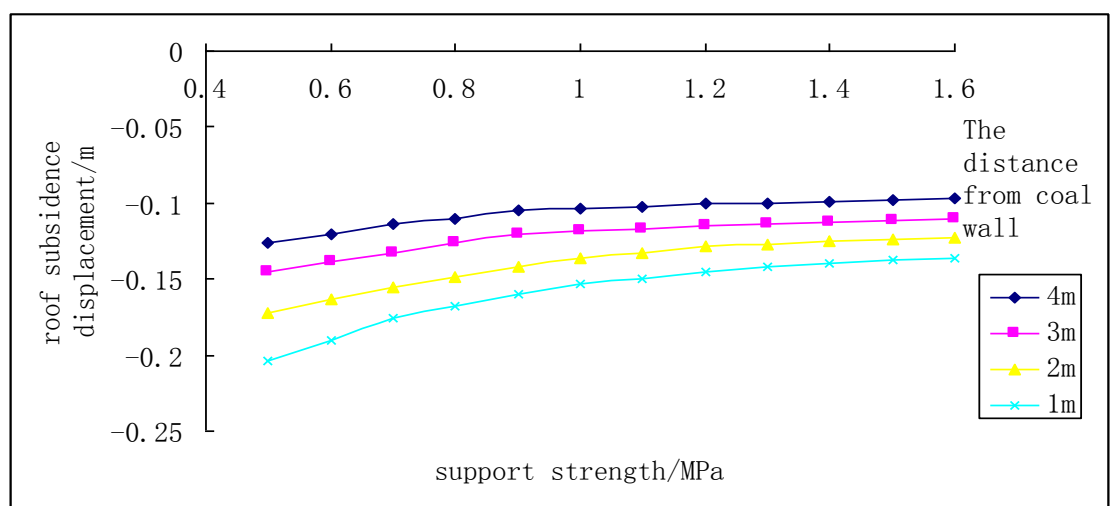

Fig. 2 The Relationship Diagram between Support Strength and Roof Subsidence Displacement

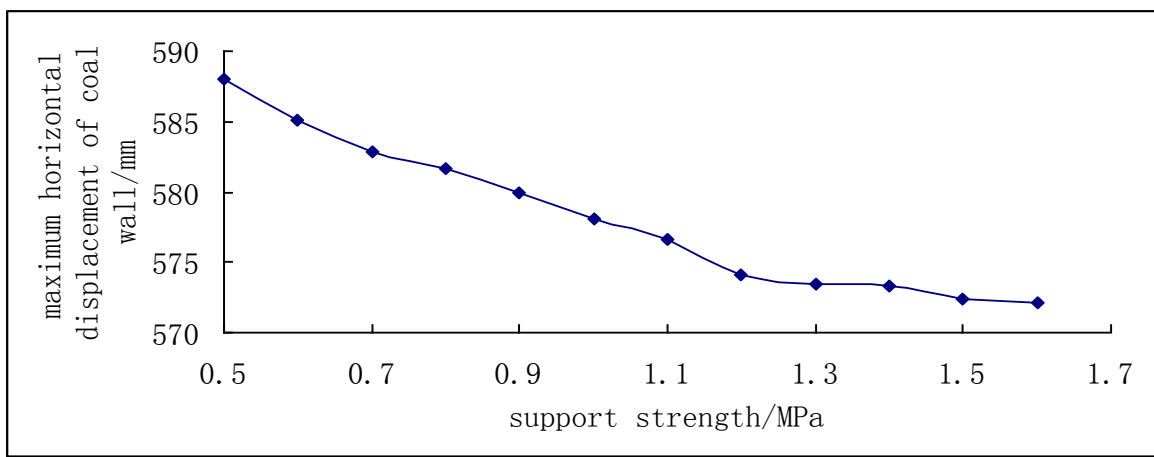

Fig. 3 The Maximum Horizontal Displacement Diagram with Different Support Strength

The results show that, with the supporting strength increasing, the roof subsidence quantity and the maximum horizontal displacement of coal wall decrease, when the supporting strength is more than 1.2MPa, the deformation curve tends to be smooth, it suggests that increasing the supporting strength can control the subsidence of roof and horizontal displacement of coal wall effectively, when the support strength increasing, the impact on the roof subsidence displacement is much bigger than one on the coal wall horizontal displacement. At the same time, when the support strength is increased to a certain level, the control effect will gradually weaken. The research results show that, increasing the support strength appropriately is beneficial to reduce the coal wall pressure and prevent coal wall spalling failure.

\section{Effect of Support Resistance of Side Protecting Plate on the Stability of the Coal Wall}

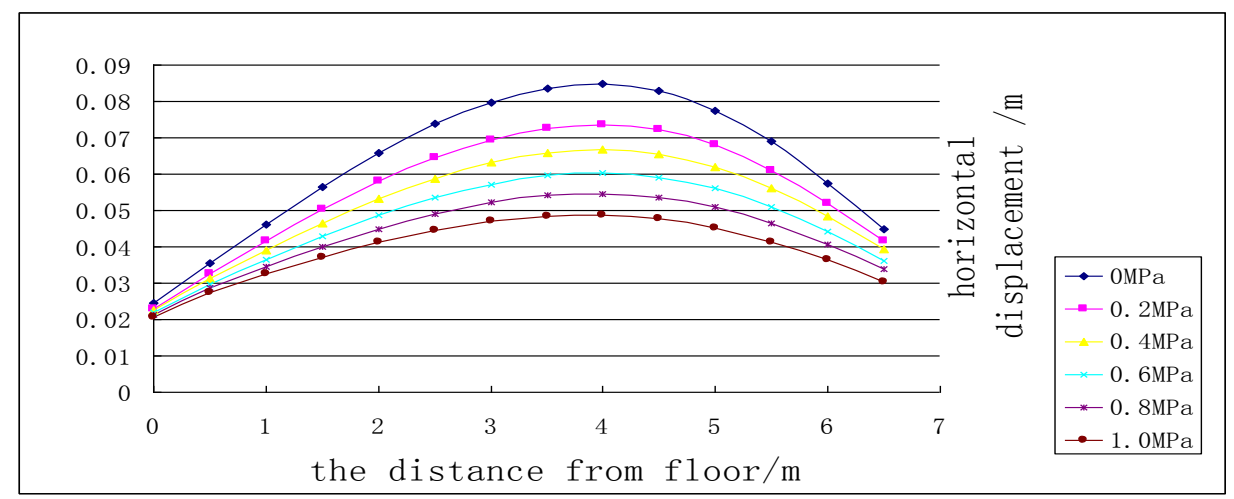

Fig. 4 Relationship Diagram between Support Resistance and Coal Wall Horizontal Displacement

Figure 4 shows the horizontal displacement curve of coal wall under the different support resistance of side protecting plate. It can be seen from the figure, with the support resistance increasing, coal wall displacement has been effectively controlled, because of the increase of support strength and area, adds a lateral force for the coal wall, make the coal wall in three dimensional stress 
state, to improve the compressive strength of coal wall [6]. The function of enhancing the support resistance is to reduce the coal wall plastic width, thereby reducing the possibility of coal wall spalling.

\section{Effect of Grouting Reinforcement on the Stability of the Coal Wall}

By mining all height at one time, the coal body bear the high concentration of stress, take the plastic deformation, due to the development of Internal joint fracture of coal body, leads to the decrease of the bearing capacity, so the stability of coal wall weaken. Thus, we can improve the stability by changing the coal properties. Figure 5 and figure 6 show that coal wall vertical stress distribution curve and the distribution of horizontal displacement characteristic curve under the grouting and no grouting conditions.

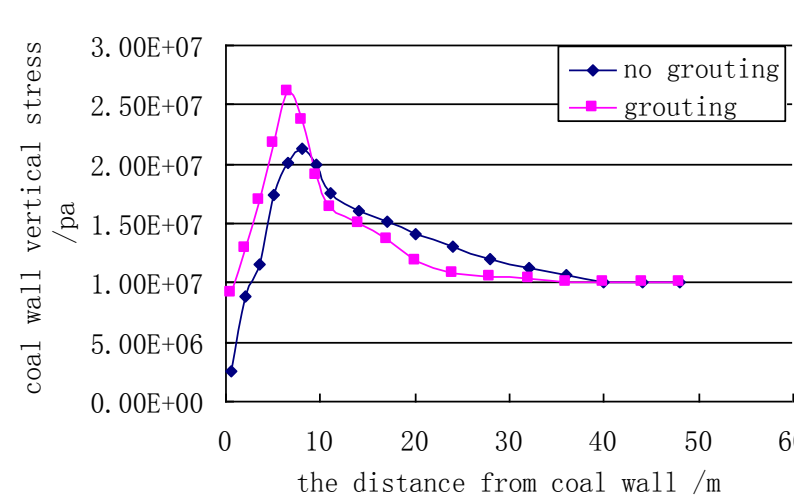

Fig. 5 Coal Wall Vertical Stress Curves

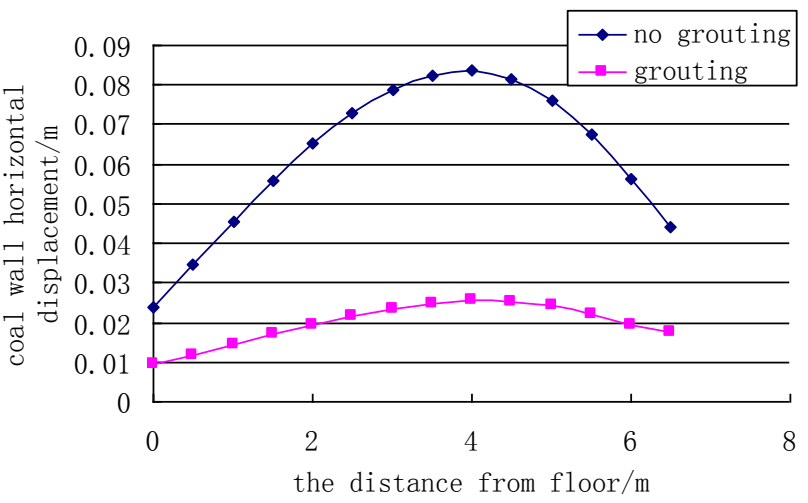

Fig. 6 Horizontal Displacement Curves

As can be seen from the graph, after grouting reinforcement, vertical stress at the edge of coal wall has been greatly improved, and high stress range is greatly decreased, which is due to taking the grouting reinforcement measures, make the coal wall body stiffness has been improved to a great extent, so the bearing capacity is also improved, reduce the coal wall plastic damage range. At the same time, taking the grouting reinforcement measure can effectively reduce the coal wall horizontal displacement deformation, has important significance for improving the stability of surrounding rock.

Figure 7 shows the plastic failure distribution range of coal wall under the two conditions. Without grouting condition, the maximum plastic failure depth is about $8 \mathrm{~m}$, the damage area reaches $46 \mathrm{~m}^{2}$. As comparison, taking the grouting reinforcement, coal wall plastic damage area is greatly reduced, the maximum failure depth is only about $2 \mathrm{~m}$, the damage area is also reduced to $16 \mathrm{~m}^{2}$, it shows that the coal wall spalling area has greatly reduced and the possibility has become smaller.

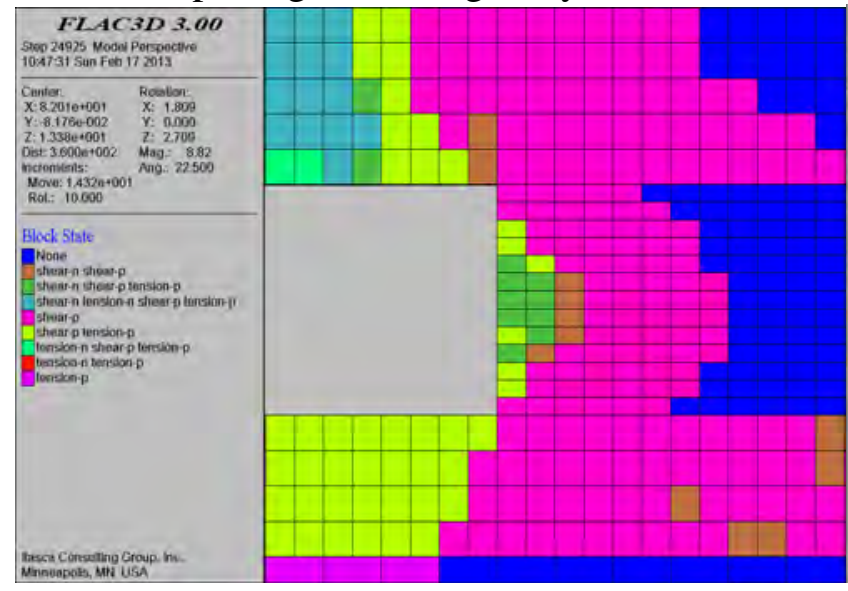

(a) No grouting reinforcement

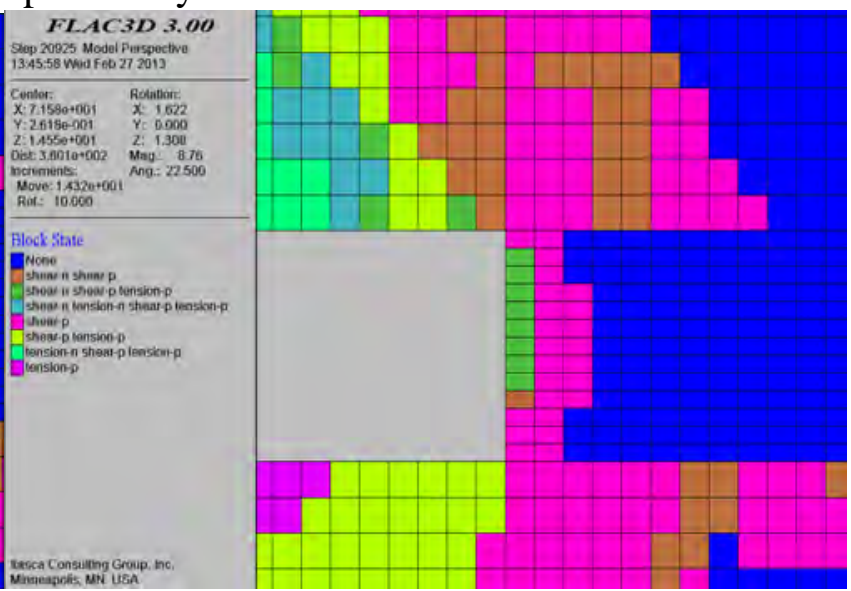

(b) Grouting reinforcement

Fig. 7 The Plastic Failure Distribution Range of Coal Wall under the Two Conditions 


\section{The Engineering Practice and Application Effect}

\section{Engineering Application}

According to the actual situation of Wang Zhuang coal mine 7105 full-seam mining working face, propose the following technical measures to control coal wall stability.

1) Increase the support resistance

According to the results of numerical simulation, the rational supporting strength is determined as 1.2MPa, and consider the affluent coefficient $10 \%$, the hydraulic support of Wang Zhuang coal mine 7105 full-seam mining working face should reach 1.32MPa.According to the following formula to calculate the support resistance.

$$
P=q \cdot\left(L_{K}+L_{D}\right) \cdot B \text {. }
$$

In the formula, $P$ - the support resistance, $\mathrm{kN} ; q$-support strength, $1.32 \mathrm{MPa} ; L_{K}$-the distance from beam, $0.65 \mathrm{~m} ; L_{D}$-support beam length, $4.6 \mathrm{~m} ; \quad B$-support width, $1.75 \mathrm{~m}$

Bring these parameters into the formula (7):

$$
P=1.32 \times 1000 \times(0.65+4.6) \times 1.75=12128 k N
$$

Based on the above results, considering a certain coefficient, the support resistance is determined as $13000 \mathrm{kN}$, safety valve opening pressure as $46.9 \mathrm{MPa}$.

2) Use the three levels side supporting design [7]

In order to control the surrounding rock stability, the hydraulic support use the three levels side supporting design, the structure includes three side protection plates and a hydraulic cylinder. The side protection plate is installed at the front of the support beam to protect the coal wall. The height of protection plates should reach $3.5 \mathrm{~m}$; support strength should be no less than $0.85 \mathrm{MPa}$.

3) Speed up the working face mining, when necessary, using the step coal cutting

Because coal wall spalling has timeliness, should try to speed up the working face mining, reduce various kinds of abnormal accidents which cause the mining shutdown. Stop production should choose to be in the place where the coal seam is thin and the roof condition is good. When the coal wall spalling phenomenon is serious, we can use the step coal cutting method, mainly leave the bottom coal to form step, and then cut the top coal. This method can reduce the mining height and improve the surrounding rock stability.

4) Use the coal wall grouting reinforcement technology

Tab. 1 The Grouting Parameters

\begin{tabular}{|c|c|c|c|c|c|}
\hline Design mode & $\begin{array}{c}\text { Height } \\
{[\mathrm{m}]}\end{array}$ & $\begin{array}{c}\text { Angle } \\
{\left[{ }^{\circ}\right]}\end{array}$ & $\begin{array}{c}\text { Hole depth } \\
{[\mathrm{m}]}\end{array}$ & $\begin{array}{c}\text { Diameter } \\
{[\mathrm{mm}]}\end{array}$ & $\begin{array}{c}\text { Space between } \\
{[\mathrm{mm}]}\end{array}$ \\
\hline single row drilling & $\begin{array}{c}\text { far away from } \\
\text { roof } 3.5\end{array}$ & 35 & $6 \sim 7$ & 60 & 3000 \\
\hline
\end{tabular}

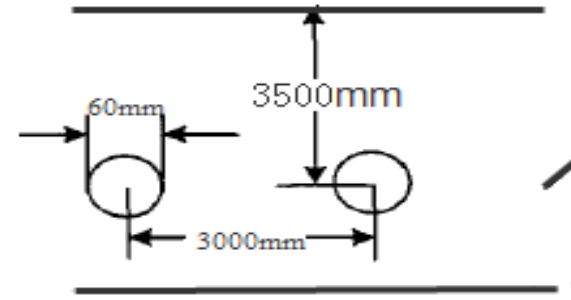

(a) plan graph

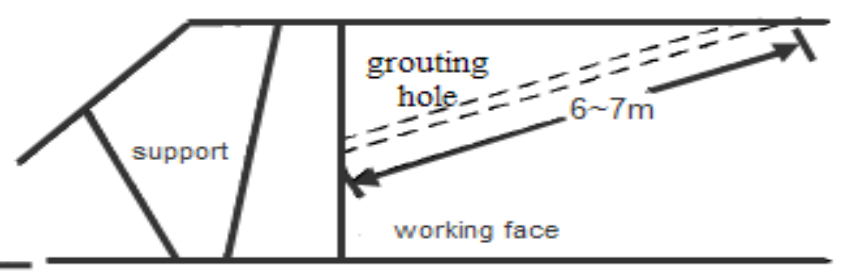

(b) profile chart

Fig. 8 Layout of Grouting Holes on the Coal Wall 
Because the $3 \#$ coal seam is very soft, with the $6.5 \mathrm{~m}$ height mining, the coal wall spalling possibility will greatly increase. So we decide to choose the high water injecting plastic material on 7105 large mining height fully-mechanized working face. Calculated by formula (6), the plastic width of coal wall is $5.03 \mathrm{~m}$. It can be sure that the coal wall pre-grouting range is about $5 \mathrm{~m}$, the grouting hole is away from the roof $3.5 \mathrm{~m}$, grouting hole layout with single row drilling method. The grouting parameters and grouting holes layout are showed by table 1 and figure 8 .

\section{Application Effect}

In order to test the result of coal wall spalling control on Wang Zhuang coal mine 7105 working face, arrange 5 test stations (No.5, No.31, No.66, No.95, and No.121 support) to detect the changes of coal wall spalling depth. Result is as below in figure 9.

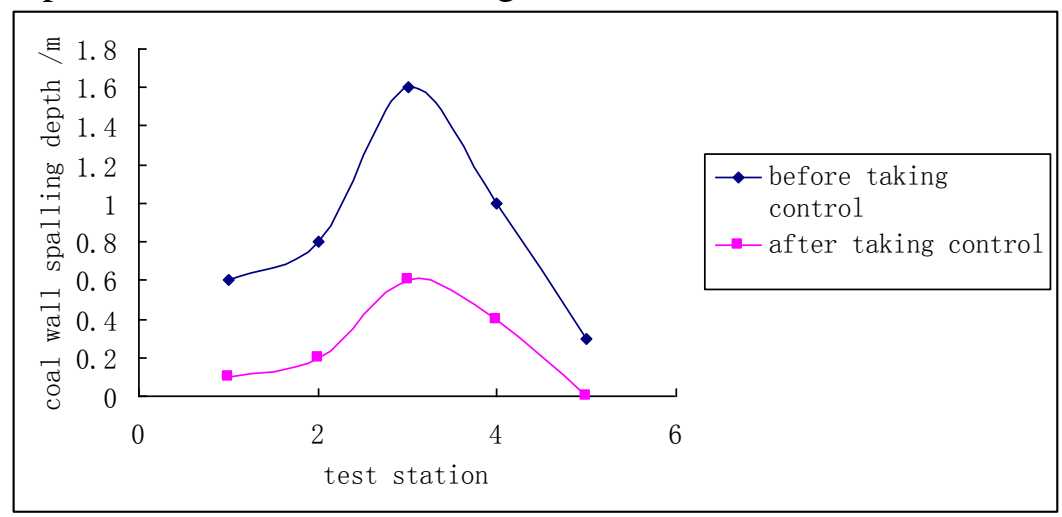

Fig. 9 Monitoring Curves for Coal Wall Spalling Depth

As can be seen, after taking measures the coal wall spalling depth has been effectively controlled, the maximum spalling depth decreases from $1.6 \mathrm{~m}$ to $0.6 \mathrm{~m}$, the average depth decreases from $0.9 \mathrm{~m}$ to $0.3 \mathrm{~m}$, spalling range has changed from $90 \%$ down to $35 \%$. It shows that, the coal wall stability control measures have achieved good results on Wang Zhuang coal mine 7105 working face.

\section{Conclusion}

1) Combined with Lade-Duncan strength criterion under plane strain condition, the coal wall spalling mechanism has been analyzed, the width of plastic zone and stress distribution has been studied, has identified the strength of the support, side protecting plate resistance, strength of coal body, coal mining height and depth of coal seam are several important factors that affect the coal wall spalling.

2) Numerical simulation results show that, increasing the support strength, using side supporting design and taking coal wall grouting reinforcement can reduce the coal wall pressure, prevent coal wall spalling failure, improve stability of the coal wall.

3) In the actual situation of Wang Zhuang coal mine 7105 full-seam mining working face, put forward to the control measures and reasonable parameters, and through the field monitoring test, have obtained the good feedback results, it has provided effective technical guarantee for thick coal seam in Wang Zhuang coal mine.

\section{References}

[1]YUAN Yong, TU Shi-hao, MA Xiao-tao, SUN Lu-lu, BAI Qing-sheng. Coal Wall Stability of Fully Mechanized Working Face with Great Mining Height in "Three Soft" Coal Seam and Its Control Technology [J]. Journal of Mining \& Safety Engineering, 2012, (01):21-25.

[2]YANG Pei-ju, LIU Chang-you, WU Feng-feng. Breakage and falling of a high coal wall in a thick mined seam[J]. Journal of China University of Mining \& Technology, 2012, (03):371-377. 
[3]YUAN Qian-jin. Prevention and theoretic analysis of rib fall in fully mechanized caving face[J]. Coal Science \& Technology Magazine, 2009, (02):44-47

[4]Gao Wei. The elastic-plastic analysis on stability of inclined coal[J]. Mechanics and Engineering, 2001(23), 23-26.

[5]Jiang Qiang, Zhu Jian-ming, Yao Yang-ping. Application of Lade-Duncan failure criterion to calculation of bearing capacity of foundation $[\mathrm{J}]$. Chinese Journal of Rock Mechanics and Engineering, 2005, 24(18) : 3262-3265.

[6]YIN Zhipo. The Analysis and Prevention of the Rib Fall in the Big Shear Height Fully Mechanized Coal Face[J]. Journal of North China Institute of Science and Technology, 2008, (03):51-53.

[7]NIU Yan-qi, CHEN Shu-y, LIU Jun-feng. Analysis on Spalling Increased Mechanism of Fully Mechanized High Cutting Coal Mining Face and Prevention Measures[J]. Coal Science and Technology, 2010, (07):38-40+64. 